\title{
Laparoscopic evaluation of female infertility in low socioeconomic status
}

\author{
Chesta Saini $^{1}$, Ashoo Gupta ${ }^{1}$, Kishore Rajurkar ${ }^{1}$, Kartik Saxena ${ }^{2}$, \\ Kanchan Saini ${ }^{3}$, Rijul Saini ${ }^{2 *}$
}

\begin{abstract}
${ }^{1}$ Department of Obstetrics and Gynecology, ${ }^{2}$ Department of Minimal Access and General Surgery, Sanjay Gandhi Memorial Hospital, Delhi, India

${ }^{3}$ Department of Obstetrics and Gynaecology, Bhagwan Mahavir Hospital, Delhi, India
\end{abstract}

Received: 29 May 2018

Accepted: 05 June 2018

\author{
*Correspondence: \\ Dr. Rijul Saini, \\ E-mail: rijulsaini@gmail.com
}

Copyright: () the author(s), publisher and licensee Medip Academy. This is an open-access article distributed under the terms of the Creative Commons Attribution Non-Commercial License, which permits unrestricted non-commercial use, distribution, and reproduction in any medium, provided the original work is properly cited.

\section{ABSTRACT}

Background: Infertility is a multidimensional health issue which is rising dramatically. The common causes include ovarian, uterine, tubal disorders, hormonal imbalance, age-related factors and lifestyle factors. The low economic strata poses a subset of problems like difficulty in seeking healthcare, treatment costs and poor compliance. Authors sought to evaluate the factors for primary and secondary infertility in women of reproductive age group who belong to low socio-economic strata using laparoscopy.

Methods: A prospective observational study was conducted in the obstetrics and gynaecology department at Sanjay Gandhi memorial hospital, Delhi comprising 50 infertile women of reproductive age group belonging to low socioeconomic class for a period of 2 years from June 2015 onwards.

Results: Among primary infertility, tuberculosis (27.02\%), ovarian cyst (16.22\%), adhesions (10.81\%), polycystic ovaries $(10.81 \%)$ and Pelvic inflammatory disease $(10.81 \%)$ were the major findings whereas in secondary infertility Pelvic inflammatory disease $(23.07 \%)$, tuberculosis $(15.38 \%)$, adhesions $(15.38 \%)$ and endometriosis $(7.69 \%)$ were the major factors seen in the study.

Conclusions: Tuberculosis and pelvic inflammatory disease were the major factors seen in infertile women of low socioeconomic status thus, they should be kept high on the list of differential diagnosis even if the investigative work up is negative.

Keywords: Infertility Laparoscopy, Low socioeconomic status, Primary, Secondary

\section{INTRODUCTION}

Since the beginning of the recorded history, the human race has placed emphasis on infertility. Nothing more vividly demonstrates the importance of fertility to an individual than the reaction by and to those who do not have children. Infertility affects about $10-15 \%$ of couples showing that it is a common problem. ${ }^{1}$ According to the International Committee for Monitoring Assisted
Reproductive Technology and the World Health Organisation, infertility is 'a disease of the reproductive system defined by the failure to achieve a clinical pregnancy after 12 months or more of regular unprotected sexual intercourse'. ${ }^{2}$ while, the National Institute for Clinical Excellence (NICE) defines it as failing to get pregnant after two years of regular unprotected sex. ${ }^{3}$ It is termed as primary if conception has never occurred, and secondary if the patient fails to conceive after having 
achieved a previous conception irrespective of the outcome. $^{3}$

The prevalence of infertility ranges from $3.5 \%$ to $16.7 \%$ in developed nations and from $6.9 \%$ to $9.3 \%$ in less developed nations, with an estimated overall median prevalence of $9 \% .^{4}$ There is escalating incidence of infertility in India. According to Delhi IVF Infertility Research Centre, infertility affects as many as one in six couples. The recent National Family Health Survey (NFHS) estimated childlessness as $2.4 \%$ of currently married women over 40 in India. ${ }^{5}$

Infertility is caused by male and/or female factors. The common factors responsible for infertility in females are ovulatory disorders, tubal factors, endometriosis, uterine and cervical factors. ${ }^{6}$ Untreated pelvic inflammatory disease (PID), post abortal, postpartum infections and tuberculosis are common factors of infertility in developing countries. ${ }^{7}$

The number of couples seeking medical help for infertility is increasing dramatically. ${ }^{8}$ In $90 \%$ of the cases the cause is identifiable and in $50 \%$ of the cases appropriate therapy will result in pregnancy. ${ }^{9,10}$ Frequently, problems that cannot be discovered by an external physical examination or other radiological investigations can be discovered by laparoscopy and hysteroscopy, two procedures that provide a direct look at the pelvic organs.

Until recently, laparoscopy was the final diagnostic procedure of the female fertility exploration, as outlined by the American Fertility Society in 1992 and by the World Health Organisation guidelines. ${ }^{11}$ In 1997, Glatstein et al reported that $89 \%$ of all reproductive endocrinologists in the USA routinely performed a laparoscopy in the diagnostic work-up of infertility. ${ }^{12}$

Considering the above facts, the present study was undertaken to evaluate the factors for infertility in women of low socio-economic status using laparoscopy.

\section{METHODS}

This prospective observational study was conducted in the Department of Obstetrics and Gynaecology at Sanjay Gandhi Memorial Hospital (SGMH), Delhi for a duration of two years from June 2015 to June 2017.

\section{Sample size}

A total of 50 women with primary or secondary infertility belonging to low socio-economic strata were selected. Considering the confidence level at $95 \%$ and the width of confidence interval at 0.10 , the sample size was calculated using the following formula:

$\mathrm{n}=1.962 \times 4 \mathrm{p}(1-\mathrm{p}) / \mathrm{d}^{2}$ where, $\mathrm{n}$ - sample size; $\mathrm{p}$ - expected population proportion; $d$ - desired width of confidence interval

Using the values of expected population proportion $(\mathrm{p}=$ 0.11 ) and width of confidence interval $(0.10)$ in the above formula:

$\mathrm{n}=1.962 \times 4 \times 0.11(1-0.11) /(0.10)^{2}=1.962 \times 4 \times 0.11 \times$ $0.89 \times 100=76.83$

Thus, maximum value of $\mathrm{n}$ comes out to be about 77 . But, due to time constraints and keeping the departmental statistics of previous 2 years of our hospital into account (approx. 3 to 4 cases per month and 30 cases per year), the sample size of 50 was determined.

\section{Inclusion criteria}

- Married women from the age of 18 to 40 years with primary/secondary infertility willing for infertility workup

- Normal semen analysis of the husband.

\section{Exclusion criteria}

- Severe cardiac / respiratory illness

- Acute pelvic infection

- Uncontrolled diabetes mellitus

- Active Tuberculosis

- Multiple intestinal surgery

- Morbid obesity with BMI >40

- Patient not willing for surgery.

Women fulfilling the selection criteria were explained about the nature of the study and a written informed consent was obtained.

\section{Statistical analysis}

The data obtained was coded and entered in Microsoft Office Excel spreadsheet. Continuous data was reported as mean $\pm \mathrm{SD}$ and range. Data was analysed using Statistical Package for Social Sciences (SPSS version 20.0 for Windows, SPSS inc., IBM, Armonk, NY) statistical software. The categorical data was expressed as rates, ratios and proportions and continuous data was expressed as mean \pm standard deviation (SD).

Women who were willing and consenting to participate in the study were enrolled. Then, a detailed history was taken including the demographic details, developmental history, marital history, sexual history, menstrual history, obstetric history, past history, family history and personal history. Socioeconomic status was calculated according to the modified BG Prasad's socioeconomic scale. Detailed clinical examination was done. Sexual development of the patient was staged according to Tanner's staging. ${ }^{13}$ Cervical hostility factors were assessed if required. Apart from detailed history and 
clinical examination couple also under-went evaluation of ovulation, tubal patency and male factor by seminal fluid analysis.

Prior to laparoscopy, patients underwent three cycles of ovulation induction unless other factors indicated laparoscopy to be done early. Premenstrual endometrial biopsy was done and sent for histopathological evaluation along with $\mathrm{ZN}$ staining (for acid fast bacilli) and mycobacterial culture to rule out tuberculosis. A course of antibiotics- doxycycline and metronidazole was given for 14 days to patients. The data obtained was recorded on a predesigned and pretested proforma.

The selected women were subjected to the following investigations preoperatively:

- Complete hemogram

- Renal function tests

- Liver function tests

- Serum electrolytes

- Blood sugar

- HIV, HBsAg, VDRL, Anti-HCV

- Coagulation profile

- Urine routine and microscopy

- Urine culture and sensitivity if Urinary tract infection (UTI) suspected

- $\quad$ Chest X-ray, Electrocardiogram (ECG)

- Hormonal Assay as per patient profile

- Ultrasound (USG) whole abdomen and pelvis

- Hysterosalpingography

All patients were sent for a pre-anaesthetic check up to anaesthesia department. All patients received a dose of prophylactic antibiotic (inj. Ceftriaxone $1 \mathrm{~g}$ iv stat) 30 minutes before starting the procedure and tablet Misoprostol 400 micrograms was kept per vaginally.

Laparoscopy was done under general anaesthesia in early proliferative phase of menstrual cycle in semi lithotomy with slight trendelenburg position. Pneumoperitoneum was created with a Veress needle after assuring correct placement using $\mathrm{CO}_{2}$ gas through a small infraumbilical incision. Continuous flow of $\mathrm{CO}_{2}$ was maintained at the rate of $200 \mathrm{ml} / \mathrm{min}$ and pressure at $15-25 \mathrm{~mm} \mathrm{Hg}$.

Trocar and laparoscope insertion followed through the same skin incision. One $5 \mathrm{~mm}$ working port was inserted in all patients. Additional $5 \mathrm{~mm}$ working ports were inserted if required for further treatment. Under fibre optic illumination, inspection was done for any pelvic abnormality like abnormality in the uterus, fallopian tubes, ovaries, utero-sacral pouch and pouch of Douglas.

Both ovaries were examined regarding shape, size, and their relationship with fimbrial end of the tubes. Peritoneal, peri ovarian and omental adhesions, tuboovarian masses, endometriotic deposits, fibroids, presence of fluid in pouch of Douglas or any other pathology was noted and biopsy was taken for any suspicious nodule or tubercle and sent for histopathology, gram staining and $\mathrm{ZN}$ staining. Whereas cystic fluid was sent for cytology. Cervical dilatation was done, and methylene blue dye was injected through leech-wilkinson cannula to look for patency of fallopian tubes. Treatment was offered to the patient in the same sitting as per requirement.

At the end of the procedure, after proper inspection of the peritoneal cavity, gas was expelled from the peritoneal cavity and the incision site was sutured.

Post-operatively the patients were kept for 24 hours in the ward if no therapeutic procedure is done. For other patients, hospital stay varied according to the therapeutic procedure done or complications encountered. Postoperatively the patients received intra-venous antibiotics (Inj. Ceftriaxone 1g IV twice a day), analgesics (Inj. Diclofenac 1 amp IV 12 hourly), and Inj. Ranitidine 1 amp IV 12 hourly and monitored for vitals.

\section{RESULTS}

The data obtained was analysed and the final results and observations were interpret-ed as below.

In the present study, most of the women had primary infertility $(74.00 \%)$.

Table 1: Distribution of women according to the type of infertility.

\begin{tabular}{|lll|}
\hline Type of infertility & Distribution $(\mathrm{n}=50)$ \\
\hline Primary & 37 & Percentage \\
\hline Secondary & 13 & 74.00 \\
\hline Total & 50 & 26.00 \\
\hline
\end{tabular}

Table 2: Age wise distribution of women with infertility.

\begin{tabular}{|lll|}
\hline $\begin{array}{l}\text { Age group } \\
\text { (Years) }\end{array}$ & Distribution $(\mathrm{n}=\mathbf{5 0})$ \\
\hline 21 to 25 & 4 & Percentage \\
\hline 26 to 30 & 30 & 8.00 \\
\hline 31 to 35 & 13 & 60.00 \\
\hline 36 or more & 3 & 26.00 \\
\hline Total & 50 & 6.00 \\
\hline
\end{tabular}

The mean age was $29.54 \pm 3.33$ years.

Peritoneal adhesions were seen in $16.22 \%$ of patients with primary infertility as com-pared to $23.08 \%$ of those with secondary infertility; peritoneal inclusion cyst was noted in $8.11 \%$ in primary and $7.69 \%$ in secondary infertility. 
Table 3: Distribution of women according to the laparoscopic findings and type of infertility.

\begin{tabular}{|c|c|c|c|c|c|}
\hline \multirow{2}{*}{ Laparoscopy } & \multirow{2}{*}{ Findings } & \multicolumn{2}{|c|}{ Primary infertility $(n=37)$} & \multicolumn{2}{|c|}{ Secondary infertility ( $n=13$ ) } \\
\hline & & No & $\%$ & No & $\%$ \\
\hline \multirow[t]{6}{*}{ Peritoneum } & Normal & 25 & 67.57 & 8 & 61.54 \\
\hline & Tubercles & 2 & 5.41 & 0 & 0.00 \\
\hline & Adhesions & 6 & 16.22 & 3 & 23.08 \\
\hline & Endometriosis & 1 & 2.70 & 1 & 7.69 \\
\hline & Peritoneal inclusion cyst & 3 & 8.11 & 1 & 7.69 \\
\hline & Total & 37 & 100.00 & 13 & 100.00 \\
\hline \multirow[t]{5}{*}{ Uterus } & Normal in shape and contour & 34 & 91.89 & 11 & 84.62 \\
\hline & Anatomical malformation & 1 & 2.70 & 0 & 0.00 \\
\hline & Fibroid & 1 & 2.70 & 0 & 0.00 \\
\hline & Tubercles & 1 & 2.70 & 2 & 15.38 \\
\hline & Total & 37 & 100.00 & 13 & 100.00 \\
\hline \multirow[t]{6}{*}{ Ovaries } & Normal & 23 & 62.16 & 12 & 92.31 \\
\hline & Polycystic or bulky & 4 & 10.81 & 0 & 0.00 \\
\hline & Ovarian cyst & 6 & 16.22 & 0 & 0.00 \\
\hline & Periovarian adhesions & 2 & 5.41 & 1 & 7.69 \\
\hline & Endometriotic cyst & 2 & 5.41 & 0 & 0.00 \\
\hline & Total & 37 & 100.00 & 13 & 100.00 \\
\hline \multirow[t]{8}{*}{ Fallopian tube } & Normal in appearance & 19 & 51.35 & 8 & 61.54 \\
\hline & Unilateral hydro salpinx & 2 & 5.41 & 1 & 7.69 \\
\hline & Bilateral hydro salpinx & 3 & 8.11 & 0 & 0.00 \\
\hline & Tubercles & 0 & 0.00 & 1 & 7.69 \\
\hline & Peri tubal adhesions & 6 & 16.22 & 1 & 7.69 \\
\hline & Bilateral tubo-ovarian mass & 3 & 8.11 & 1 & 7.69 \\
\hline & Beaded appearance & 4 & 10.81 & 1 & 7.69 \\
\hline & Total & 37 & 100.00 & 13 & 100.00 \\
\hline \multirow[t]{5}{*}{ Chromopertubation } & Bilateral free spill of dye seen & 22 & 59.46 & 6 & 46.15 \\
\hline & Unilateral spill of dye & 3 & 8.11 & 1 & 7.69 \\
\hline & Absent spill of dye & 7 & 18.92 & 4 & 30.77 \\
\hline & Loculated spill of dye & 5 & 13.51 & 2 & 15.38 \\
\hline & Total & 37 & 100.00 & 13 & 100.00 \\
\hline
\end{tabular}

Table 4: Distribution of women according to type and cause of infertility based on laparoscopic findings.

\begin{tabular}{|lllll|}
\hline $\begin{array}{l}\text { Cause of } \\
\text { infertility }\end{array}$ & \multicolumn{2}{l}{$\begin{array}{l}\text { Primary } \\
\text { infertility }(\mathbf{n}=\mathbf{3 7})\end{array}$} & $\begin{array}{l}\text { Secondary } \\
\text { infertility } \\
(\mathbf{N}=\mathbf{1 3})\end{array}$ \\
\hline Normal & 5 & $\mathbf{\%}$ & $\mathbf{N o}$ & $\mathbf{\%}$ \\
\hline TB & 10 & 27.02 & 2 & 15.38 \\
\hline $\begin{array}{l}\text { Endometrial } \\
\text { synechiae }\end{array}$ & 0 & 0.00 & 3 & 15.38 \\
\hline PID & 4 & 10.81 & 3 & 23.07 \\
\hline PCOD & 4 & 10.81 & 0 & 23.07 \\
\hline Adhesions & 4 & 10.81 & 2 & 15.38 \\
\hline Ovarian cyst & 6 & 16.22 & 0 & 0.00 \\
\hline $\begin{array}{l}\text { Uterine } \\
\text { malformation }\end{array}$ & 1 & 2.70 & 0 & 0.00 \\
\hline s & & 8.11 & 1 & 7.69 \\
\hline Endometriosis & 3 & 100.00 & 13 & 100.00 \\
\hline Total & 37 & 13 & & \\
\hline
\end{tabular}

Tubercles over uterus were noted in $2.7 \%$ of women with primary infertility and $15.38 \%$ with secondary infertility.
Peri-ovarian adhesions were noted in $5.41 \%$ of women with primary infertility in contrast to $7.69 \%$ of women with secondary infertility; whereas polycystic ovaries $(10.81 \%)$, ovarian cyst $(16.22 \%)$ and endometriotic cyst (5.41) were seen only in primary infertility.

Bilateral hydrosalpinx was seen only in primary infertility $(8.11 \%)$; peritubal adhesions were seen in $16.22 \%$ of women with primary infertility, bilateral tuboovarian mass was not-ed in $8.11 \%$ with primary infertility and $7.69 \%$ with secondary infertility. Chromopertubation showed absent spill of dye in $18.92 \%$ with primary infertility and $30.77 \%$ with secondary infertility; loculated spill of dye was seen in $13.51 \%$ of women with primary infertility and $15.38 \%$ of women with secondary infertility (Table 3).

In this study, laparoscopy revealed normal study in $13.51 \%$ of women with primary infertility and $15.38 \%$ of women with secondary infertility. Most common cause of infertility in women with primary infertility was tuberculosis $(27.02 \%)$, followed by ovarian cyst (16.2\%) whereas amongst women with secondary infertility, 
Pelvic Inflammatory disease $(23.07 \%)$ and endometrial synechiae $(23.07 \%)$ were the most common factors seen (Table 4).

\section{DISCUSSION}

Infertility is a multidimensional health issue which occurs due to ovulation problems, tubal blockage, uterine problems, hormonal imbalance, age-related factors and lifestyle factors like higher age of people getting married along with occupational stress and non-conducive legal framework for assisted reproduction etc. ${ }^{14}$

Laparoscopy appears to be invasive, but it has the advantage of being diagnostic and therapeutic at the same sitting. Operative procedures at the time of laparoscopy can enhance conception, naturally or with IUI/IVF, such as lysis of adhesions, ablation of endometriosis, and salpingectomy for hydrosalpinx. ${ }^{15}$ However, some investigators showed that diagnostic laparoscopy did not reveal any pathology or only minimal and mild endometriosis in 40-70\% of all cases. ${ }^{16}$

The low economic strata poses a subset of problems like difficulty in seeking healthcare for infertility related issues, treatment costs, poor compliance for long duration of therapy and frequent visits to the hospital. Keeping this in mind 50 women diagnosed to have either primary or secondary infertility belonging to low socio-economic strata were studied and following were noted:

\section{Type of infertility}

In the present study, most women $(74.00 \%)$ had primary infertility. These findings were consistent with a study by Chimote A et al who encountered 63 cases of primary and secondary infertility of which 46 cases $(73 \%)$ were primary infertility and 17 cases $(27 \%)$ were secondary infertility. ${ }^{17}$ Kore $\mathrm{S}$ et al, in their study reported 34 patients had primary infertility and 6 had secondary infertility. ${ }^{18}$ Similarly, Nayak PK et al from Odisha conducted a retrospective study to determine the role of diagnostic laparoscopy in the evaluation of infertility in tertiary care centres. ${ }^{19}$ Out of 300 cases, 206 (69\%) patients had primary infertility. Recently a study by Qurat-ul-Ain W et al in from Kashmir also reported most cases $(82 \%)$ with primary infertility and $18 \%$ cases of secondary infertility. ${ }^{20}$

\section{Age}

Female age is the single most important determinant of spontaneous as well as treatment-related conception, with a gradual decline in fertility especially after the age of 35 years. ${ }^{21,22}$ However, in this study the most common age group was 26 to 30 years $(60.00 \%)$. The mean age was $29.54 \pm 3.33$ years suggestive of younger age group. Kore $\mathrm{S}$ et al in their study reported similar observation where most of the women study were between 25-30 years of age. ${ }^{18}$ The mean observed age in the present study was much lower compared to a study by Corson SL et al. where the mean age was $32.7 \pm 4.5$ years. ${ }^{23}$ The disparity in the mean age between the present study and that of Corson SL et al could be attributed to the socio-cultural practices of early marriages in India. In particular, it has been suggested that older women are more likely to be diagnosed with unexplained infertility and that is due to the negative effect of age on ovarian reserve. ${ }^{24}$

\section{Hysterosalpingography}

In the present study, hysterosalpingography revealed normal findings among $32 \%$ of the women while bilateral distal tubal blockage was the most common finding noted in more than one fourth of the women $(34.00 \%)$. The study by Chakraborti et al showed bilateral tubal block to be the most common tubal cause of Infertility. ${ }^{25}$ Sharma $\mathrm{R}$ et al studied 125 cases of infertility and the commonest cause was tubal adhesions and blockage (35.9\%). ${ }^{26}$

In this study, among the women with primary infertility, $32.43 \%$ of the women had normal findings on hysterosalpingography, while bilateral distal tubal blockage was noted in $32.43 \%$ of the women followed by unilateral distal tubal blockage $(18.92 \%)$, cornual blockage $(13.51 \%)$ and bicornuate uterus $(2.7 \%)$. In contrast to these observations, a study by Chimote A. et al reported that $33 \%$ of the women with endometriosis, $11 \%$ with pelvic tuberculosis, $4 \%$ with tubal block and $13 \%$ were with normal findings in the primary infertility group. ${ }^{17}$ Among women with secondary infertility, hysterosalpingographic findings showed the most common abnormality as bilateral distal tubal blockage (38.46\%). Naz T et al (2009) found bilateral tubal blockage in $28.07 \%$ cases of secondary infertility. ${ }^{27}$

\section{Diagnostic laparoscopy}

In present study, normal laparoscopic findings were seen in $18 \%$ of the women which is comparable to a study by Chimote $\mathrm{A}$ et al where authors reported normal findings in $13 \%$ of the women. ${ }^{17}$

In the present study, $18 \%$ of the women had peritoneal adhesions, followed by peritoneal inclusion cyst in $8 \%$, endometriosis and tubercles were seen in $4 \%$ of the women. With respect to uterus, tubercles and fibroid were noted in $6 \%$ and $2 \%$ of the cases respectively. $12 \%$ of the women had ovarian cyst and $8 \%$ of the women had polycystic or bulky ovaries, peri-ovarian adhesions were noted in $6 \%$ of the women and endometriotic cyst in $4 \%$. Peri-tubal adhesions were seen in $14 \%$ of the women, $10 \%$ of the women had beaded appearance of the fallopian tubes, $8 \%$ of the cases had bilateral tuboovarian mass, $6 \%$ of the women each had bilateral and unilateral hydrosalpinx. With respect to Chromopertubation, no spill of dye was seen in $22 \%$ of women, loculated spill of dye in $14 \%$ of the cases and unilateral spill of dye was found in $8 \%$ of the women. 
Tubal and peritoneal pathologies are amongst the most common causes of infertility seen in approximately 30 $35 \%$ of couples. ${ }^{28}$ A provisional diagnosis of tuberculosis the study was made on finding unilateral/bilateral hydrosalpinx, tubo-ovarian mass, beaded appearance of fallopian tubes along with tubercles. Pelvic Inflammatory Disease was diagnosed in patients with unilateral/bilateral hydrosalpinx, tubo-ovarian mass with flimsy adhesions or clear fluid filled peritoneal cysts. Tuberculosis was further confirmed by histopathological and microbiological methods.

Recently Jain G et al analysed the results of 203 women, on whom, laparoscopy for the evaluation of infertility was done and observed that tubal disease was the responsible factor in $62.8 \%$ women with primary infertility and $54.8 \%$ women with secondary infertility followed by pelvic adhesions in $33 \%$ and $31.5 \%$, ovarian factor in $14 \%$ and $8.5 \%$, pelvic endometriosis in $9.9 \%$ and $6.1 \%$ women respectively which was consistent with the present study. ${ }^{29}$

In contrast to the findings of the present study, Kausar N, et al reported leading causes of infertility as endometriosis and fibroid of the uterus. ${ }^{30}$ Other prevalent causes of infertility noted were pelvic inflammatory disease $(6.9 \%$ in primary infertility and $18.5 \%$ in secondary infertility), pelvic tuberculosis (in primary infertility) and polycystic ovaries (46.5\% in primary and $30 \%$ in secondary infertility).

Another study by Nousheen Aziz et al on 50 patients concluded that most common causes responsible for infertility were tubal occlusion, endometriosis, peritubal and periovarian adhesions. ${ }^{31}$

\section{CONCLUSION}

During the study strict asepsis was maintained and all precautions were taken however, one patient $(2 \%)$ had uterine perforation and another one paralytic ileus which got settled in the ward with conservative management using antibiotics and careful monitoring.

Postoperative complications with laparoscopy are very low which corresponds with the findings of few other national and international studies. ${ }^{32-34}$ The major risk is damage to the bowel, bladder, ureters, uterus, major blood vessels or other organs. Certain conditions may increase the risk of serious complications like previous abdominal surgery, especially bowel surgery, and a history or presence of bowel/pelvic adhesions, severe endometriosis, pelvic infections, obesity, or excessive thinness. Allergic reactions, nerve damage and anaesthesia related complications rarely occur. Postoperative urinary retention is uncommon and venous thrombosis (blood clot) is rare. ${ }^{35}$ Thus, with this study it may be concluded that:
- Laparoscopy is an important tool to investigate female factor infertility as many findings which cannot be diagnosed by other investigations can be picked up on laparoscopy and few can be treated in the same sitting as well with minimal complications.

- The major factors for primary infertility were Tuberculosis (27.02\%), Ovarian cyst (16.2\%), Pelvic Inflammatory Disease $(10.81 \%)$, Adhesions (10.81\%), Polycystic ovarian disease $(10.81 \%)$ and Endometriosis $(8.11 \%)$.

- The factors for secondary infertility were Pelvic Inflammatory Disease $(23.07 \%)$, Endometrial Synechiae (23.07\%), Tuberculosis (15.38\%), Adhesions (15.38\%) and Endometriosis (7.69\%).

- On the basis of our study, laparoscopy suggested that Tuberculosis (24\%), Pelvic Inflammatory Disease (14\%), Adhesions (12\%), Ovarian cyst (12\%) and Endometriosis $(8 \%)$ were the major factors responsible for infertility in women of low socioeconomic status.

Funding: No funding sources

Conflict of interest: None declared

Ethical approval: Not required

\section{REFERENCES}

1. Boivin J, Bunting L, Collins JA, Nygren KG. International estimates of infertility prevalence and treatment-seeking: Potential need and demand for infertility medical care. Hum Reprod. 2007; 22:150612.

2. Gurunath S, Pandian Z, Anderson RA, Bhattacharya S. Defining infertility: a systematic review of prevalence studies. Hum Reprod Update 2011;17(5):575-88.

3. Zegers-Hochschild F, Adamson GD, de Mouzon J, Ishihara O, Mansour R, Nygren K, et al. International Committee for Monitoring Assisted Reproductive Technology; World Health Organization. International Committee for Monitoring Assisted Reproductive Technology (ICMART) and the World Health Organization (WHO) revised glossary of ART terminology, 2009. Fertil Steril. 2009;92(5):1520-4.

4. Boivin J, Bunting L, Collins JA, Nygren KG. International estimates of infertility prevalence and treatment-seeking: potential need and demand for infertility medical care. Hum Reprod. 2007;22(6):1506-12.

5. Dutta S, Guha R. A clinico-anatomical study on the common etiological factors pertaining to primary infertility in females using some common investigative procedures. $J$ Anat Soc India. 2007;56(2):14-7.

6. Jose Miller AB, Boyden JW, Frey KA. Infertility. Am Fam Physician. 2007;75:849-56.

7. Rehana R, Majid SS. Aetiological factors of infertility. J Postgrad Med Inst. 2004;18:166-71. 
8. Winfield AC, Fleischer AC, Moore DE. Diagnostic imaging of fertility disorders. Curr Probl Diagn Radiol. 1990;19(1):1-38.

9. Ali S, Sophie R, Imam AM, Khan FI, Ali SF, Shaikh A, et al. Knowledge, perceptions and myths regarding infertility among selected adult population in Pakistan: a cross-sectional study. BMC Public Health. 2011;11(1):760.

10. Callahan LT, Caughey AB. Infertility and assisted reproductive technologies: Blueprints Obstetrics and Gynecology. Lippincott Williams and Wilkins; 2008;275-89.

11. Rowe PJ, Comhaire FH, Hargreave TB, Mahmoud AMA. WHO manual for the standardized investigation of the infertile couple. Cambridge, UK: Cambridge University Press Cambridge; 1993.

12. Glatstein IZ, Harlow BL, Hornstein MD. Practice patterns among reproductive endocrinologists: the infertility evaluation. Fertil Steril. 1997;67:443-51.

13. Marcus E. Setchell. Pre-operative Assessment and Diagnostic Procedures. In: Marcus E. Setchell, John H. Shepherd, editors $7^{\text {th }}$ edition. Shaw's Textbook of Operative Gynaecology. 2013;34-6.

14. Sudha G. Reddy KSN. Causes of female infertility: a cross-sectional study. Int J Latest Res Sci Technol. 2013;2(6):119-23.

15. Fouany, MR, Muasher SJ. Is there a role for laparoscopy in the diagnosis and treatment of infertility in the $21^{\text {st }}$ century? Middle East Fertil Soc J. 2010;15:146-52.

16. Forman RG, Robinson JN, Mehta Z, Barlow DH. Patient history as a simple predictor of pelvic pathology in subfertile women. Hum Reprod. 1993;8:53-5.

17. Chimote A, Samal S, Hariharan C, Angik R. Laparoscopy and hysteroscopy in patients of infertility in a rural set up. Int J Reprod Contracept Obstet Gynecol. 2015;4:322-8.

18. Kore S, Aparna H, Sudha N, VR Ambiye, PR Vaidya. Sonosalpingography for assessment of tubal patency: Our experience. J Obstet Gynecol India. 2000;50(2):63-6.

19. Nayak PK, Mahapatra PC, Mallick J, Swain S, Mitra S, Sahoo J. Role of diagnostic hysteron-laparoscopy in the evaluation of infertility: a retrospective study of 300 patients. J Hum Reprod Sci. 2013;6(1):32-4.

20. Qurat-ul-Ain W, Ara R, Dangroo SA, Beig M. Diagnostic Laparoscopy in the Evaluation of Female Factors in Infertility in Kashmir Valley. Int $\mathrm{J}$ Women's Health Reprod. 2014;2(2):48-57.
21. Menken J, Trussell J, Larsen U. Age Infert Sci. 1986; 233(4771):1389-94

22. Templeton A, Morris JK, Parslow W. Factors that affect outcome of in-vitro fertilization treatment. Lancet. 1996;348(9039):1402-6.

23. Corson SL, Cheng A, Gutmann JN. Laparoscopy in the normal infertile patient; a question revisited. J Am Gynaecol Laparose. 2000;7(3):317-24.

24. Botting B, Dunnell K. Trends in fertility and contraception in the last quarter of the $20^{\text {th }}$ century. Popul Trends. 2000;(100):32-9.

25. Chakraborti DK, Kole SK. Diagnostic laparoscopy in gynecologic disorders. J Obstet Gynecol India. 1990;40:262-5.

26. Sharma R, Sharma V. The infertile women: a study of 120 cases. J Indian Med Assoc. 1991;89(2):31-2.

27. Naz T, Hassan L, Gulmeen, Nighat F, Sultan S. Laparoscopic evaluation in infertility. J Coll Physicians Surg Pak. 2009;19(11):704-7

28. Kumar P, Malhotra N, (editors). Jeffcoates Principles of Gynaecology. $7^{\text {th }}$ ed., New Delhi. Jaypee Brothers Medical Publishers; 2008.

29. Jain G, Khatuja R, Juneja A, Mehta S. Laparoscopy: as a first line diagnostic tool for infertility evaluation. J Clin Diag Res. 2014;8(10):1-2.

30. Kausar N, Hussain U, Riaz T, et al. Operative Evaluation of Infertile Females. J F J M C 2010;4(3):17-21.

31. Nousheen Aziz. Laparoscopic Evaluation of Female Factors in Infertility. J Coll Physicians Surgeons Pakistan. 2010;20(10):649-52.

32. Marcoux S, Maheux R, Bérubé S. Laparoscopic surgery in infertile women with minimal or mild endometriosis. N Eng J Med. 1997;337(4):217-22.

33. Cahill DJ, Wardle PG. Management of infertility. Br Med J. 2002;325:28-32.

34. Popovic J, Sulovic V, Vucetic D. Laparoscopy treatment of adnexal sterility. Clin Exp Obstet Gynecol. 2005;32(1):31-4.

35. Laparoscopy and hysteroscopy - a guide for patients. Alabama; American Society for Reproductive Medicine; 2012.

Cite this article as: Saini C, Gupta A, Rajurkar K, Saxena K, Saini K, Saini R. Laparoscopic evaluation of female infertility in low socioeconomic status. Int J Reprod Contracept Obstet Gynecol 2018;7:3232-8. 